\title{
'All Walks of Life', A Profile of Household Insurance Fraudsters in the United Kingdom
}

\author{
MARK BUTTON, FRANCIS PAKES AND DEAN BLACKBOURN, Centre for Counter Fraud Studies, \\ University of Portsmouth; Portsmouth, UK
}

\section{ABSTRACT}

This paper provides a profile of a household insurance fraudster based upon an analysis of 33,189 dishonest household insurance claims identified by VFM Ltd. VFM Ltd provides a claims handling service to a wide range of insurers which uses the conversation management process to identify higher risk claims, which has built up a substantial database of claims, some of which were made available to the researchers. The data shows some differences from profiles of occupational fraudsters, with greater gender equality. The peak age range of claimants is 30-50 and there a diverse range of occupations amongst the claimants. Claims made are also generally low, at less than f500. The paper also offers insights on the goods claimed, the excuses and the timing. The paper also suggests household insurance fraud can be linked to Routine Activity Theory with evidence to suggest dishonest claimants are from all walks of life and the offending occurs as part of their everyday life.

Key words: insurance fraud, profile, Routine Activity Theory, offenders

\section{Introduction}

Insurance fraud and fraud more generally has been the subject of only limited research in the United Kingdom and internationally (Levi, 2008). Some of the limited research on insurance fraud has examined the nature of the problem and strategies to deal with it (see Clarke, 1989, 1990; Gill et al, 1994; Doig et al, 1999; Litton, 2000; Morley et al, 2006; Palasinski, 2009; Smith et al 2010). The industry has also sought recently to more accurately measure the costs of fraud and gauge public attitudes towards it in the UK (Association of British Insurers 2012a and 2003). There has, however, been very little research into those who actually commit insurance fraud recently and drawing upon a large sample. For example Gill et al (1994) found 58 respondents in a survey of 638 who admitted some form of insurance fraud and Dodd (1998) is only study which has sought to profile insurance fraudsters, but it is dated and based upon only 209 claims (only 60 percent of which were household). Reference will, however, be made to this study as the findings unfold later in the paper. Indeed for fraud more generally there has only been limited interest in fraudsters, which has tended to focus upon occupational fraudsters (Kapardis, and Krambia-Kapardis, 2004; Bussmann and Werle, 2006; ACFE, 2012; Warfield, 2012). This paper will seek to start to fill that gap in research by offering findings from an analysis of over 30,000 dishonest household insurance claims which begins to offer insights on the profile of a household insurance fraudster. The findings also suggest household insurance fraud is a crime largely perpetrated by ordinary people (rather than professional criminals) 
during the course of their everyday, life supporting some of the findings of Cohen and Felson (1979) relating to Routine Activity Theory, Felson and Clarke (1998) relating to opportunity and Karstedt and Farrall (2006) relating to significant numbers of the population willing to engage in 'crimes of everyday life'. This research is unique in the sense that it uses a very large dataset of individuals who have submitted claims, which could be regarded as dishonest and fraudulent. This paper will utilise this unique dataset to outline some of the characteristics of household insurance fraudsters.

This paper will start by examining insurance and evidence of the extent of this problem. The paper will also explore some of the research which has been published profiling fraudsters. It will then move on to examine the methods for this paper and the nature of the dataset used. The paper then moves on to explore the profile of household insurance fraudsters.

\section{Insurance Fraud and Fraudsters}

Fraud can be defined as 'any crime which uses deception as its principal modus operandi' (Wells, 1997: 2). Insurance fraud could therefore be described as any attempt at using deception against an insurance company to secure an advantage. Smith et al (2010) have distinguished the following types of insurance fraud which are common:

- Providing false details: failing to declare motoring convictions, past claims etc to secure a lower premium .

- Forged documents and identities: using forged documents or false identities to secure insurance cover.

- Exaggerating a claim: exaggerating a legitimate claim, to secure a larger payment from the insurer than what the claimant is really entitled to.

- Making a false claim: creating a false claim to secure a payment from the insurer.

- Staging a claim: creating a real incident to secure a claim against an insurer.

More recently some insurers have also experienced a problem with fraudsters impersonating them to secure policy income for policies which do not exist. It is also important to note that fraud against insurance companies doesn't just come from their own policy holders, but also third parties. For instance insurers of companies often face a third party claim from a visitor to a company site who has injured themselves there or an insurer of a motorist frequently face a claim from someone who claims to have been hit by that motorist they insure.

There are a wide range of different types of insurance. The focus of this paper will be upon household contents insurance fraud. Household contents insurance typically covers consumer durables and valuables, such as computers, televisions, jewellery etc from theft or accidental damage. In the UK in 2011 there were 19.7 million households with such cover (Association of British Insurers, 2012b). The risk of fraud is from the policy-holder either exaggerating a legitimate claim or completely fabricating one. It would be useful now to consider the scale of insurance fraud in the United Kingdom and attitudes towards it. 
The Association of British Insurers (2012a) has found that every hour there are 15 fraudulent insurance claims detected and that in 2011 detected fraud amounted to $£ 983$ million. This represented $5.7 \%$ of all claims in 2011 and in total there were 138,814 fraudulent insurance claims that were discovered. In addition to this there are the many fraudulent claims that slip though the insurers' counter fraud controls. The ABI has suggested this could amount to another $£ 2$ billion. To put this in perspective, benefits fraud, which secures significant media and political attention, amounted to $f 1.2$ billion in 2011 (National Fraud Authority, 2012). Insurance fraud is therefore potentially double the size of benefits fraud.

There is also evidence to suggest that the general public are much more open to the idea of committing insurance fraud compared to other crimes and frauds (Gill et al 1994; Dodd, 1998). Research on the opinions of the general public has found:

- Making up an insurance claim - 37\% would not rule out committing in the future, $29 \%$ think it is acceptable or borderline and $2 \%$ admit to having done it.

- Exaggerating an insurance claim - $47 \%$ would not rule out committing in the future, $40 \%$ think it is acceptable or borderline and $6 \%$ admit to having done it.

- Using someone else's credit card - $26 \%$ would not rule out committing in the future, $6 \%$ think it is acceptable or borderline and $2 \%$ admit to having done it (Association of British Insurers, 2003).

Similar research by Karstedt and Farrall (2006) has also found that $22 \%$ of those surveyed in England and Wales would consider padding an insurance claim. There is therefore evidence that insurance fraud is a substantial problem and that many ordinary people consider it is acceptable. Before some of the findings are considered from this research it would be useful to look more generally at the profile of criminals and fraudsters.

\section{Profile of a Fraudster}

Criminal profiling has long captured the imagination of both law enforcement and the wider public (Canter, 1994; Jackson and Bekerian, 1997). True to its FBI origins, criminal profiling was initially mainly utilised in an operational context where the challenge was to make predictions about individual offenders who were at large, in particular in case of murders and sexual offences. Subsequently a statistical approach blossomed with the added advantage that it brought knowledge about offenders and offending behaviour at an aggregate level (e.g. Davies, 1997, Canter and Heritage, 1990). Through that approach a much wider set of criminal behaviours came under scrutiny but the field was slow to include fraud.

Writing in 2006 Kapardis and Krambia-Kapardis noted there had been little interest in profiling white collar criminals in general and fraudsters in-particular. Since that research there has not been any significant changes. The Association of Certified Fraud Examiners (ACFE) regularly produces its Report to the Nation which provides data on occupational fraudsters (ACFE, 2006, 2008, 2010 and 2012). KPMG have also published two studies offering insights on largely occupational fraudsters (KPMG, 2007 and 2011). Bussman and Werle (2006) have conducted research on an international basis of occupational fraudsters. In Australia Warfield (2012) has profiled 'million dollar' occupational fraudsters. Kapadis and Krambia-Kapardis (2006: 197) found: 
the majority of serious fraud offenders are male, aged 35-45 years, married, of high educational status, either have a serious financial problem or are greedy for money, do not have a prior criminal record, occupy positions of financial trust, rationalize their behaviour, specialize in defrauding, act alone, use false documents to perpetrate fraud, victimize two or more people they know, and are convicted of multiple charges.

Some of the more recent research has confirmed some of this profile for occupational fraudsters. The table below profiles the characteristics from KPMG (2011) ACFE (2012) and Bussmann and Werle (2006). The latter also included some external fraudsters in their analysis. The ACFE study is based upon global returns and KPMG from Europe, The Middle East and Africa. The ACFE research, which is broken down into regions, also shows substantial differences between them, which there is not the space to consider here.

Table 1. Comparing the Profiles of Occupational Fraudsters

\begin{tabular}{|l|l|l|l|}
\hline & KPMG 2011 & ACFE 2012 & $\begin{array}{l}\text { Bussman and Werle } \\
2006\end{array}$ \\
\hline Gender & Male $-87 \%$ & Male $-65 \%$ & Male $-87 \%$ \\
\hline Age & $36-55-76 \%$ & $36-50-51 \%$ & $31-50-71 \%$ \\
\hline Employment & +6 Years - 50\% & +6 Years $-52 \%$ & \\
\hline $\begin{array}{l}\text { Management / Top } \\
\text { Management }\end{array}$ & $82 \%$ & $55 \%$ & $18 \%$ \\
\hline
\end{tabular}

The picture of a fraudster these studies suggest is a male, middle aged, with 6 years plus service and from a managerial position. This is not surprising given that men tend to dominate managerial positions and that it is these that generally offer opportunities to commit fraud. As the research will shortly show, the profile of a household insurance fraudster is very different.

\section{Dataset and Methods}

Since 2007 VFM Services Ltd (VFM) has processed thousands of household insurance claims through its New ERA process of conversation management (which will shortly be explained). The process results in the classification of the claim and two of those categories were of interest to the researchers: 'declined due to fraud' and 'withdrawn not plausible'. The researchers were given a database of 39,163 household contents insurance claims (no personal information relating to names and addresses was supplied in order to maintain customer anonymity and client confidentiality). These were divided into the following categories:

- Declined due to fraud: 268

- Withdrawn not plausible: 32,921

- Withdrawn no contact with customer: 1,936 
- Declined due to no policy cover: 3,010

- Withdrawn plausible: 1,028

The conversation management process results in a risk assessment of the claim and a classification. Claims where plausibility becomes an issue which meet a threshold of doubt are classified as not plausible. A higher level of evidence of doubt results in a fraud classification or if a claimant persists with what has been identified as a 'non-plausible' claim. A caveat to the data must therefore be noted that some of the lower ranking 'withdrawn not plausible' may have been assessed as such due to a claimant not articulating their claim effectively rather than dishonesty per se. Nevertheless given the assessment process used, most of the claims assessed in this category are highly likely to involve an element of dishonesty.

The framing of the Fraud Act 2006 means for a criminal prosecution to be pursued there must be some gain for the individual or loss to the insurer. As the claims have not been paid out they would not meet the requirements of the Act (Farrell et al 2007). There is no offence of attempting to defraud in England and Wales, other than as more than one person through the common law offence of Conspiracy to Defraud. It is therefore debatable whether the 'declined due to fraud' and 'withdrawn not plausible' cases would frequently meet the criminal standard for prosecution, unless they were paid out by the insurers - hence a gain and a loss. Under the civil law for fraud, A will have committed the tort of deceit (or fraud) in relation to $B$, if:

(1) He made a representation of the fact to B which was untrue; and

(2) When he made that representation to B he did not honestly believe it was true; and

(3) He intended, by making that representation to B, to induce B to act in a particular way; and

(4) B was induced to act in that way by A's representation (McBride, and Bagsshaw,2005).

These claims have failed, so have not met part 4, but it is likely that most of the claims in the first two categories 'declined due to fraud' and 'withdrawn not plausible' would meet the first three tests. As such this data should be considered as the largest dataset of information on individuals who have submitted dishonest claims which were attempted frauds, which if they had been paid could in many cases be classed as fraud at least under the civil law and possibly under the criminal law. The researchers were able to assess these claims against a range of categories such as gender, age, occupation etc. The results of this analysis will be presented shortly. However, before we consider this it would be useful to examine the process which is used to detect false claims and to give some examples.

\section{Conversation Management and the Detection of Dishonest Claims}

VFM provides New ERA conversation management services to a range of insurers. Some insurers contract out all their claims of a certain peril to VFM, others forward all cases judged as high risk. What VFM claims investigators do, is over the telephone discuss with the claimant their claim in a detailed and structured way. This enables the claim to be risk assessed effectively. Legitimate claims 
are then processed quickly, whereas higher risk claims face further scrutiny. The greater detail required from the claimant, in cases where there is dishonesty, tends to expose flaws in their claim.

Consider for example a case where a claimant is making a claim for a flat-screen television, which has fallen off the wall. The conversation will explore this incident in detail and will discuss the location of the wall, exactly how it fell, what happened when it fell etc. In one case of this type, which was recorded and played to the researchers, the claimant revealed when the television fell there was broken glass. The claims investigator looked up the model and make of television to discover there is no such glass in that model of television. This was then revealed to the claimant who clearly sounded very uncomfortable. The crux of the conversation management process is that it does not work up to a confrontation during which a bogus claim is unambiguously exposed. Instead the claimant is left with the opportunity to supply further evidence of their version of events such as evidence of the glass in the television, by a certain date. However, most claimants whose claims are assessed as high risk decide not to pursue their case any further. In effect they are given an honourable way out, as in this case where the claimant never supplied any further information. Such claims are classified by VFM as 'withdrawn not plausible'.

This technique is reminiscent of the enhanced cognitive interview widely in use in police settings when interviewing witnesses (Milne and Bull, 1999). It is found in a range of contexts that this technique elicits more correct information from witness than a standard interview procedure (Koehnken, Milne, Memon and Bull, 1999). Received wisdom in the area that studies the detection of deception also seems to be that it is best to not focus too much on non verbal signs of deception (such as stuttering, sweating and fidgeting which are often erroneously perceived to be indicators of deceit (Vrij, 2004) but rather on what the individual actually says (Memon, Vrij and Bull, 2003; . 'Let them talk' is therefore a credo that is gaining currency (e.g. Snook, Luther, Quinlan and Milne, 2012). To illustrate the process further some of the non-plausible cases uncovered will be outlined. The following two case studies illustrate how the process works in more depth. It's important to note the researchers did not assess the company's Conversation Management System, therefore the following analysis of claims may contain cases which were not actually fraudulent. However, researchers are confident that the process of Conversation Management would have identified, in the vast majority of cases, non-plausible claims.

\section{Theft by seagull}

After accidentally washing her $£ 1,000$ gold watch in her jeans pocket, the customer left it outside to dry on the garden table. After about five hours, the customer went to get the watch, only to discover it had disappeared. When asked how this could have happened, she confirmed that it was not possible for someone to gain access to the garden from the house and that there were no signs of anyone climbing over the fences. However, she stated that they do have a problem with seagulls flying down into the garden, creating mischief. After asking for full validation and a police report, the customer rang back the next day to advise that she'd since found her watch in the shed, having forgotten she had tidied some things away and therefore the watch must have got mixed up amongst them.

\section{Unlucky laptop owner}


The customer went out cycling in the woods, carrying his laptop and smartphone with him in a backpack. He last saw both items at lunchtime, but then at around $5 \mathrm{pm}$, he noticed that the zip of the backpack was undone and that both items were missing. When asked if he'd reported the Sim card missing, he replied, 'Yes.' However, when asked for further details, he said that in fact he hadn't and had just remembered he had actually removed the Sim card that very morning, because he knew the phone wouldn't work in the woods due to poor reception. He took the phone and laptop with him merely to take and edit photos. When asked about previous claims, the customer confirmed that this was the third time he'd lost a laptop and acknowledged himself that this was 'ridiculous'.

When the claims investigator raised concerns with the claim, especially with the fact that the customer hadn't noticed the weight of the backpack altering in any way after the loss, the customer displayed deceptive behaviours. Ten minutes after completing the claim, the customer rang back to withdraw his claim, advising that the laptop had been found and handed in to the police.

\section{Profile of a Household Insurance Fraudster}

This paper will now consider some of the findings from the analysis of the data of dishonest claims. In doing so it will show the profile of a household insurance fraudster is different from an occupational fraudster and these differences the authors argue are important findings in supporting routine activity theory.

\section{Gender}

One of the most striking findings from the research is the near equal gender balance of the dishonest claimants. Here $54 \%$ were male and $46 \%$ female. In the study by Dodd (1998) 58 percent were male, illustrating a very similar gender balance. Previous profiles of occupational fraudsters have shown a dominance of men, which has been suggested is due to their dominance of positions of responsibility enabling them to secure the opportunities to commit fraud. This research shows that once opportunities arise the sexes will pursue them in a similar way. However, an alternative hypothesis might be that 'household' matters within traditional families may be regarded as 'the female domain'. That might also help explain a relatively high involvement of women.

Both explanations would fit the criminological theory of 'Routine Activity Theory', which postulates that offending primarily occurs in the course of people's everyday life. It simply requires a motivated offender, a suitable target (the insurer may be seen as a weak and accessible target) and the perceived absence of guardians or other preventive measures (Cohen and Felson, 1979; and Felson, 2002). Given there are so many households with contents insurance this provides a suitable opportunity to target for potentially millions of policy holders. As has already been shown there is also evidence many members of the public regard insurance fraud as acceptable (Association of British Insurers, 2003; Karstedt and Farrall, 2006). Insurance companies in the past have also been reluctant to publicise their defences or those they catch, giving the impression of a lack of a capable guardian. Indeed for some there has been a preference to pay out dubious claims rather than upset customers (Clarke 1989; Morley et al 2006). As Clarke (1989: 4) noted in the late 1980s, but which is still relevant today: 
...insurance companies have a strong service ethic....The industry demonstrates utmost good faith in settling what appear to be reasonable claims on generous terms and not carping unduly. It is a view held by adjusters and claims officers equally that their objective is to cooperate with the claimant to give him compensation under the policy. Such a service ethic obviously militates against the cautious approach necessary to detect and pin down frauds.

With opportunities equally open to men and women, the gender disparity often found in fraud research seems to disappear.

It is also important to note the importance of opportunity in this type of crime. Felson and Clarke (1998) have noted the importance of opportunity in influencing levels of crime building upon extensive research. The household contents insurance policy provides a simple opportunity for many households to secure an additional payment. For the many generally law abiding citizens, insurance fraud represents an 'acceptable' crime which can be pursued with few burdens against a corporate victim which generally receives little sympathy. As Palasinski (2009: 552) has noted regarding the views of the public vis-à-vis insurance companies, 'it is also construed as a fair practice of settling old scores with big corporations viewed as unscrupulous and evil.' The 19 million plus policy-holders all have the opportunity to commit this crime. All they need to do is add additional items to a legitimate claim or fabricate a claim and contact the insurance company. For many the opportunity to secure the new television or laptop through dishonest means is only a telephone call or completed claim form away.

Figure 2. Gender of Dishonest Claimants

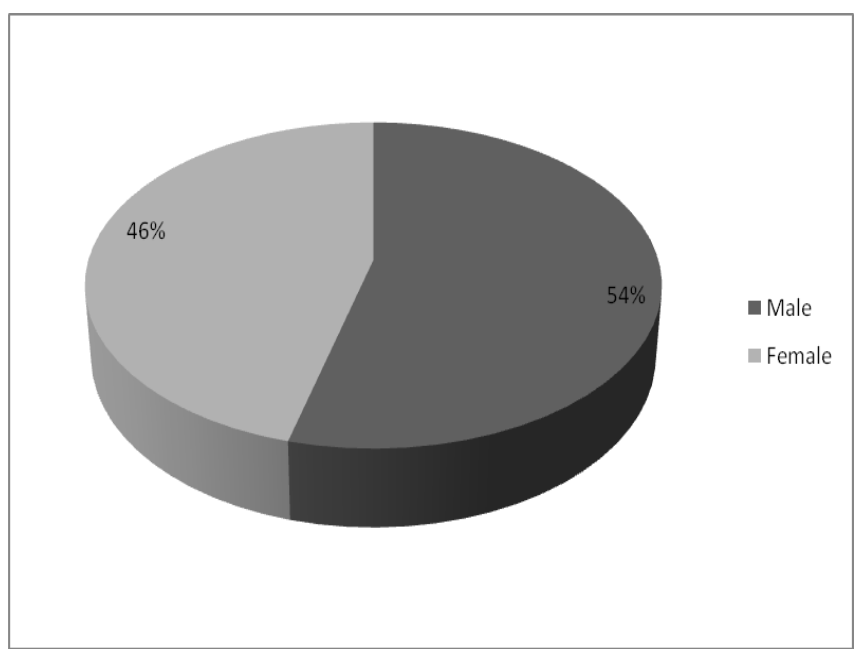

$N=31,010$

Age 
Profiles of occupational fraudsters generally show a dominance of the 30-50 age group. The research for this report also shows the biggest group falling in the 31-50 age group representing $57 \%$ of the group. Those over 50 also accounted for a significant slice, representing $29 \%$. In the age category $61+$ accounted for only $12 \%$ (this age group will be considered further under occupation). The smallest group was the 18 to 29 group representing $14 \%$. The mean age was 44 , median 43 and mode 41 years old respectively. In the Dodd (1998) study the average age was 38 with over half been 38 and over. There is a bigger younger element in the Dodd study than this one, but one must remember Dodd's study was wider than household insurance policies. Given that most claims relate to insurance products that are more likely to be held by older persons this offers further insights upon Routine Activity Theory. This age group may simply be the most likely to hold household insurance policies. Furthermore, they may feel most able to competently report a fraudulent claim with a good chance of success and withstand what they might expect to be cursory scrutiny by the insurer. Making a fraudulent claim therefore would be part and parcel of everyday life where motivation and opportunity combine to produce this behaviour; perhaps the situation is as simple as to suggest that those most likely to hold policies are also most likely to make a dubious claim.

\section{Figure 3. Age of Dishonest Claimants}

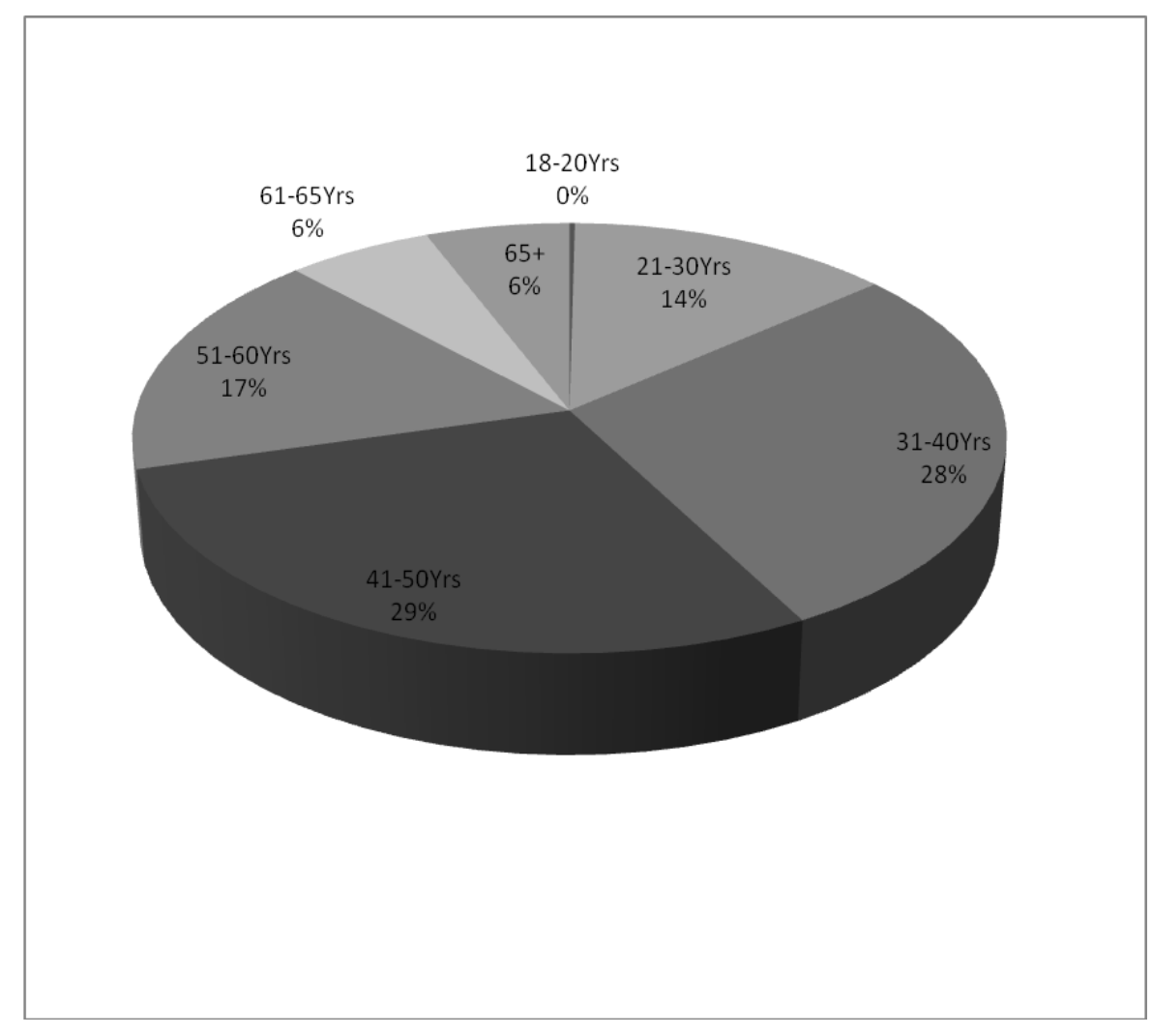

$N=24,034$

\section{Occupation}

Data was supplied by VFM on the occupations of those making a claim. The way VFM collect this data does not map across to the standard industrial classifications. The classifications VFM use, allow for potential overlap, for example some of those recorded as self-employed might also be represented in other categories. The categories of civil servant and clerical might also overlap. It is 
likely, therefore, that data collected by VFM could not be compared to those standard industrial classification groups with confidence. The table below presents some of the largest groups identified from the occupations of dishonest claimants. There was only data on 8,723 of the claims, so percentages reflect the percentage of these known claims. Thus, for the vast majority of dishonest claims there was no information on occupation. Nevertheless the range of occupations is largely reflective of society with many lower ranking occupations or those not active in the labour market, which have traditionally not featured in profiles of occupational fraudsters. This profile may therefore offer further evidence to support routine activity theory. Many people who may have limited opportunities to commit fraud in the workplace, find they so have an opportunity in their home with their contents insurance.

Table 2. Top 20 Occupations for dishonest claimants

\begin{tabular}{|l|l|l|}
\hline Rank & Occupation Classification & $\begin{array}{l}\text { Percentage of } \\
\text { Dishonest } \\
\text { Claims }\end{array}$ \\
\hline 1 & Health and caring & $9.6 \%$ \\
\hline 2 & Management & $7.7 \%$ \\
\hline 3 & Unemployed & $7.6 \%$ \\
\hline 4 & Retired & $7.3 \%$ \\
\hline 5 & Clerical & $5.6 \%$ \\
\hline 6 & Housewife/husband & $5.4 \%$ \\
\hline 7 & Self employed & $4.8 \%$ \\
\hline 8 & Financial and legal & $4.4 \%$ \\
\hline 9 & Teaching & $4.1 \%$ \\
\hline 10 & Engineering & $3.8 \%$ \\
\hline 11 & Skilled labourer & $3.8 \%$ \\
\hline 12 & Sales and marketing & $3.8 \%$ \\
\hline 13 & Retail & $3.5 \%$ \\
\hline 14 & Labourer & $3.5 \%$ \\
\hline 15 & Civil Servant & \\
\hline & & \\
\hline 10
\end{tabular}




\begin{tabular}{|l|l|l|}
\hline 16 & Transport and logistics & $3.3 \%$ \\
\hline 17 & $\begin{array}{l}\text { Hospitality and } \\
\text { entertainment }\end{array}$ & $2.0 \%$ \\
\hline 18 & IT & $1.9 \%$ \\
\hline 19 & Student & $0.9 \%$ \\
\hline 20 & Armed forces & $0.6 \%$ \\
\hline
\end{tabular}

$N=7,577$

Table 2 shows the top 20 occupations by percentage from the known data. It is important to note that this table does not mean that health and caring are the most dishonest occupations for this type of claim. To undertake that kind of analysis it would be necessary to have data on the occupations of all claimants for comparison. However, it was not possible to secure this data at this time. Another complicating factor is the data was collected over several years, when the labour statistics do vary. Despite this, the researchers did undertake a crude comparison of some of the occupations above against some labour market data, where there was a degree of comparison possible.

The results from this analysis are set out in table 3 . They show selected occupations where some comparison was possible, their percentage of dishonest claimants and the ratio of dishonest claims to the percentage of the population over 16 .

As noted above, ideally there would be a comparison to actual policyholders by occupation, but this data was not available. Clearly there are some occupations that are more likely to have insurance than others. Students would be an example where the prevalence of dishonesty would be expected to be lower because there are fewer students with household insurance policies (and it is much lower). Setting this aside, however, some broad similarity could be expected for many occupations. The third column in table 3 shows the ratio. If the percentage of dishonest claims matches the percentage of the population over 16 the score would be 1 . If it is less than one it would suggest that this group has less dishonest claims, if it is greater than one it shows it has more dishonest claims than would be expected in the population.

The data shows that students at 0.2 , the retired at 0.36 , sales and marketing at 0.79 and clerical at 0.86 have less dishonest claims than their size in the population would suggest. This does not necessarily mean these groups are more honest, because of the lack of data on actual holdings of insurance policies of this type amongst these groups. It is also likely that students are less likely to have household insurance policies, which could account for their under-representation. This could also account for the retired too, but with these it could also confirm evidence that the older generations are more honest [or could be reflective of the fact that insurers are reluctant to refer elderly customers into a fraud screening process]. For example research by Whiteley (n.d.) has suggested older people are more honest than younger. 
For those occupations with a suggestion of a more dishonest profile, the most prominent was armed forces with a ratio of 1.7, i.e. they were over 1 and half times higher than what would be expected given their size in the population over 16. Health and caring had a ratio of 1.47, unemployed 1.46, teaching 1.41 and management 1.31. The breadth of the industrial classifications, which cover health and caring and management and the way these are collected by VFM make us less confident of these figures. However, teaching, unemployed and armed forces are much clearer to classify. The unemployed could include many without household insurance, so this could make them an even bigger risk. All the other occupations are also likely to represent those who are householders who are likely to have household insurance. Therefore, with all these groups there could be a suggestion of greater dishonesty. This is, however, clearly an area that requires more research and better data collection related to standard industrial employment categories.

Table 3. Selected categories assessment for comparison to dishonest claimants (Labour Market Statistics, June 2012)

\begin{tabular}{|c|c|c|c|}
\hline & $\begin{array}{l}\% \text { of Dishonest } \\
\text { Claims }\end{array}$ & $\begin{array}{l}\% \text { of those over } \\
16\end{array}$ & $\begin{array}{l}\text { \% dishonest } \\
\text { claims / \% of } \\
\text { population } \\
\text { over } 16\end{array}$ \\
\hline Retired & $7.3 \%$ & $20.2 \%$ & $0.36 \%$ \\
\hline Unemployed & $7.6 \%$ & $5.2 \%$ & $1.46 \%$ \\
\hline Students & $0.9 \%$ & $4.4 \%$ & $0.20 \%$ \\
\hline $\begin{array}{l}\text { Health and } \\
\text { caring }\end{array}$ & $9.6 \%$ & $6.5 \%$ & $1.47 \%$ \\
\hline Management & $7.7 \%$ & $5.9 \%$ & $1.31 \%$ \\
\hline Armed forces & $0.6 \%$ & $0.35 \%$ & $1.7 \%$ \\
\hline Clerical & $5.6 \%$ & $6.4 \%$ & $0.88 \%$ \\
\hline Teaching & $4.1 \%$ & $2.9 \%$ & $1.41 \%$ \\
\hline $\begin{array}{l}\text { Sales and } \\
\text { marketing }\end{array}$ & $3.8 \%$ & $4.8 \%$ & $0.79 \%$ \\
\hline
\end{tabular}

$N=4,111$

Value of claim made 
VFM largely deal with claims under $£ 10,000$. Most of the claims related to items such as televisions, computers, jewellery etc, therefore it was unlikely to show a large number of dishonest claims of significant amounts. The median claim was for $£ 500$, mean $£ 716$ and mode $£ 501$. The distribution of claims showed $50 \%$ were $f 500$ or less, $34 \%$ were $f 501$ to $£ 1000$ and the rest were $f 1000$ or more. Perhaps what is illuminating about these findings is that psychological experiments have shown that individuals are more likely to be dishonest with small amounts, than large amounts. Tests have been conducted on similar groups of individuals who are given opportunities to cheat and as the amount they can gain goes up, the level of dishonesty goes down slightly (Mazar and Ariely, 2006; Ariely, 2012). Perhaps claimants therefore see $f 500$ as a relatively small sum of money and worth the chance of securing, compared to putting in a claim for several thousand pounds.

Figure 4. Value of claim made by dishonest claimants

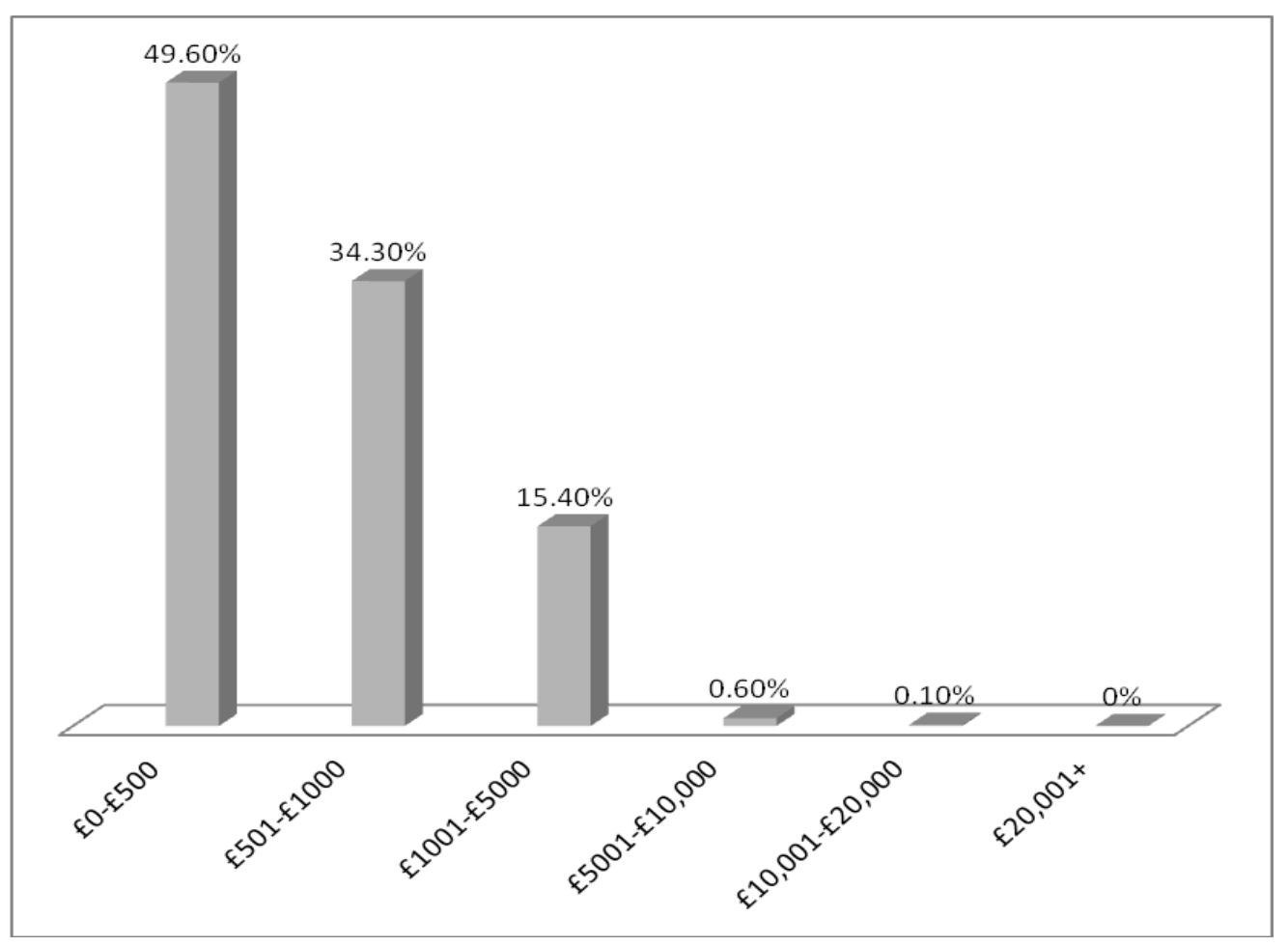

$\mathrm{N}=33,115$

\section{Type of commodity claim made for}

Table 4 shows the most common commodities for dishonest claims. The top three were computers, televisions and mobile phones. These were then followed by multiple items, jewellery, home furnishings, other, bicycles, money and then audio systems. 
Table 4. Top 10 commodities for dishonest claimants

\begin{tabular}{|l|l|l|}
\hline Rank & Commodity & Percentage \\
\hline $\mathbf{1}$ & Computers & $25.7 \%$ \\
\hline $\mathbf{2}$ & Television & $17.8 \%$ \\
\hline $\mathbf{3}$ & Mobile Phones & $14.1 \%$ \\
\hline $\mathbf{4}$ & Multiple Items & $11.1 \%$ \\
\hline $\mathbf{5}$ & Jewellery & $11.0 \%$ \\
\hline $\mathbf{6}$ & $\begin{array}{l}\text { Home } \\
\text { Furnishings }\end{array}$ & $8.2 \%$ \\
\hline $\mathbf{7}$ & Other & $2.7 \%$ \\
\hline $\mathbf{8}$ & Bicycles & $2.5 \%$ \\
\hline $\mathbf{9}$ & Money & $0.8 \%$ \\
\hline 10 & Audio Systems & $0.7 \%$ \\
\hline
\end{tabular}

$N=7,709$

\section{Length of time from opening policy to claim}

Figure 5 shows just over $50 \%$ of claimants had submitted a claim within one year of opening the policy, with just over $30 \%$ within 6 months. This would suggest claims made on a policy within a year of opening would seem to be at higher risk for fraud. However, it is also important to note that with the emergence of price comparison websites, customers changing insurance providers has become much more common, so this might just be a feature of the more common changes that occur. 
Figure 5. Period of time before dishonest claim made

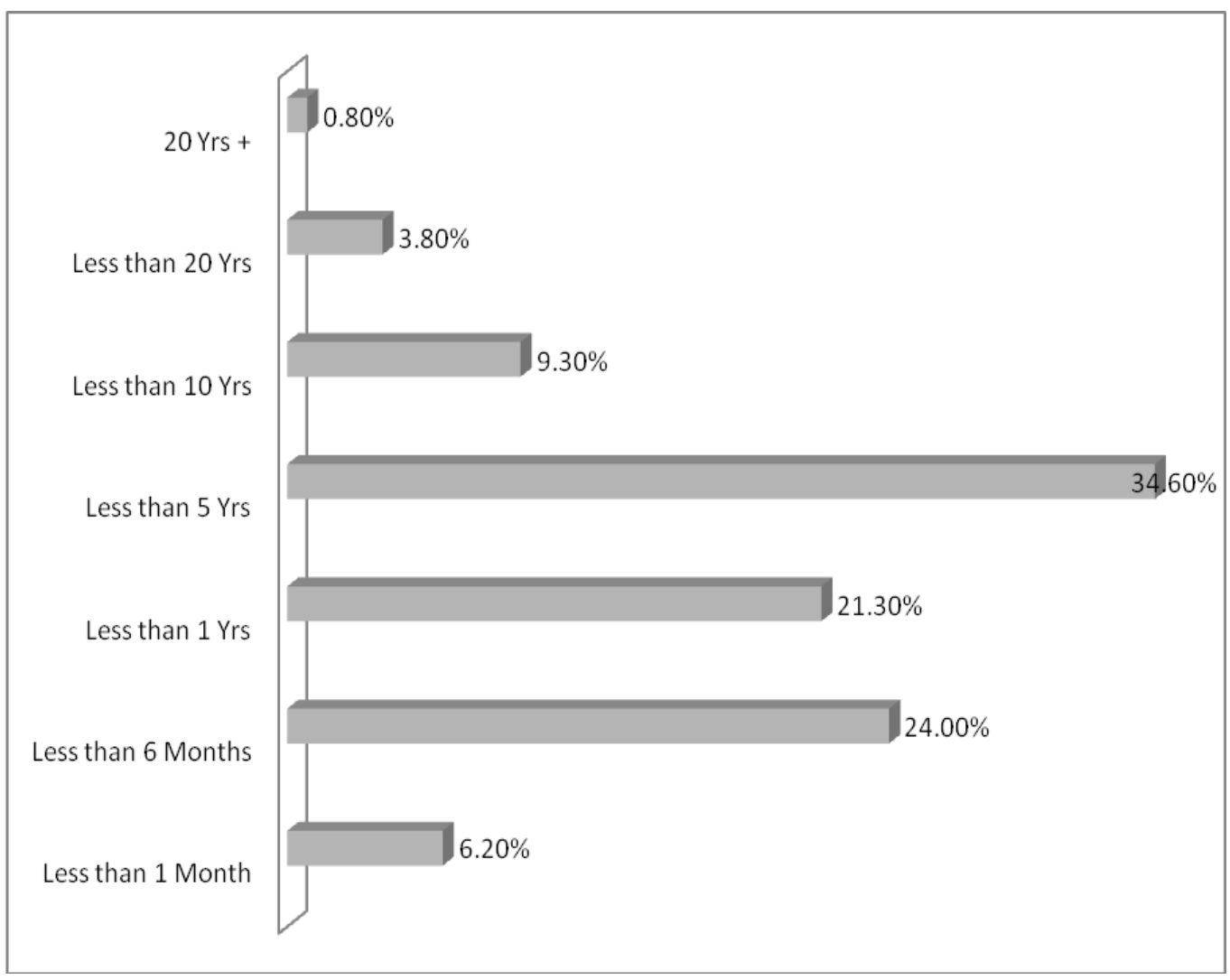

$\mathrm{N}=31,901$

\section{Number of previous claims made}

Another interesting finding was the significant number of 'virgin' claimants. When gaps in information were screened out, just under three-quarters had never made a claim before and when those who had made one previous claim were added, it rose to $90 \%$. This may also support routine activity theory suggesting everyday people deciding it's time to 'cash in' their insurance policy when times are hard, rather than organised fraudsters submitting multiple claims. 


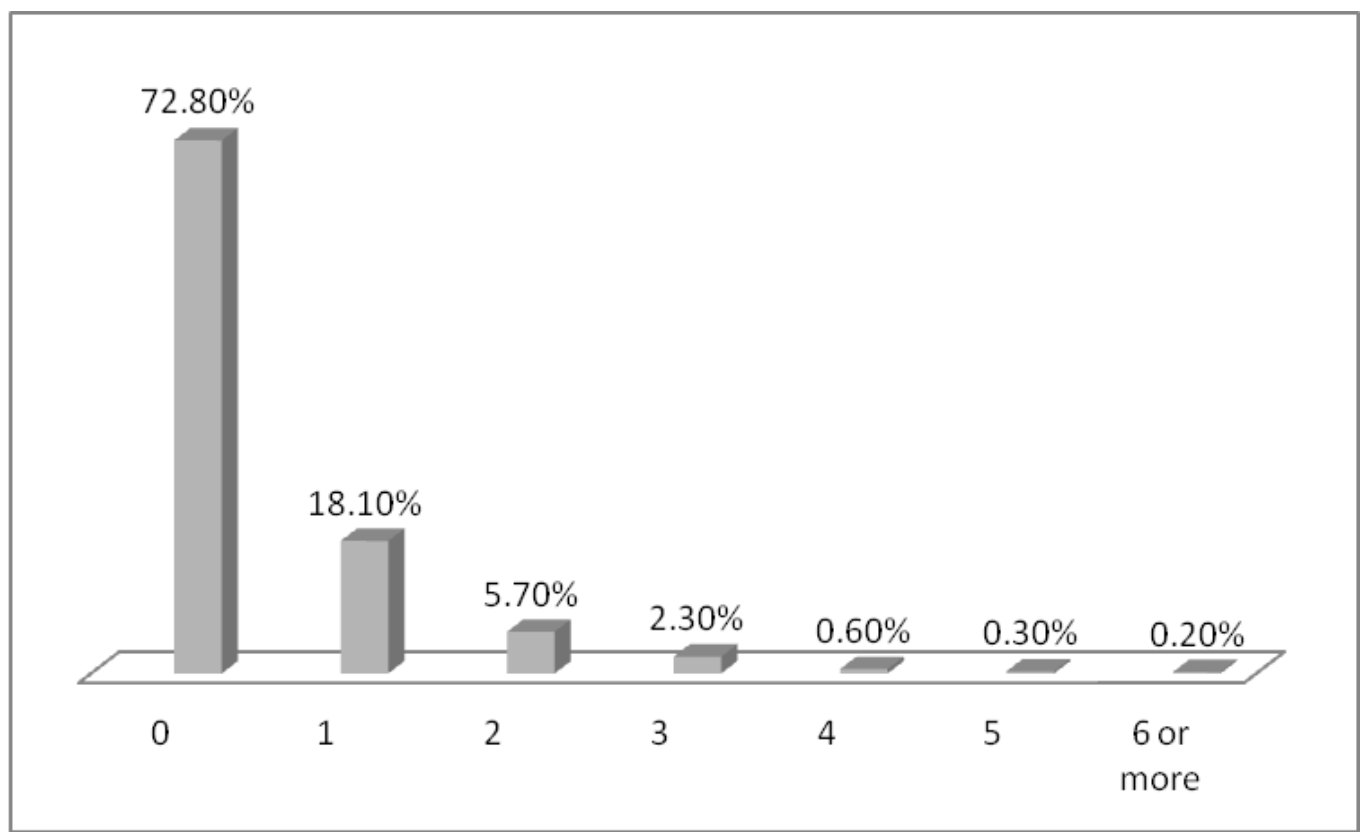

$\mathrm{N}=11,623$

\section{The non-plausible scenario [Peril]}

Fabricating an insurance claim involves inventing an event that is covered or adapting and embellishing one that has occurred. By far the most common choice of scenario was found to be some form of accident. Here $85 \%$ of claims were in this category, followed by $12 \%$ through theft. This is also the least risky because fabricating a crime involves reporting it to the police, which increases the risk of getting caught as well as committing another crime with potentially more severe consequences ('wasting police time', 'perverting the course of justice'). This perhaps also offers further evidence to support 'Routine Activity Theory' in that most are choosing scenarios where the capable guardian is weakest. 
Figure 7. Claimants' excuses

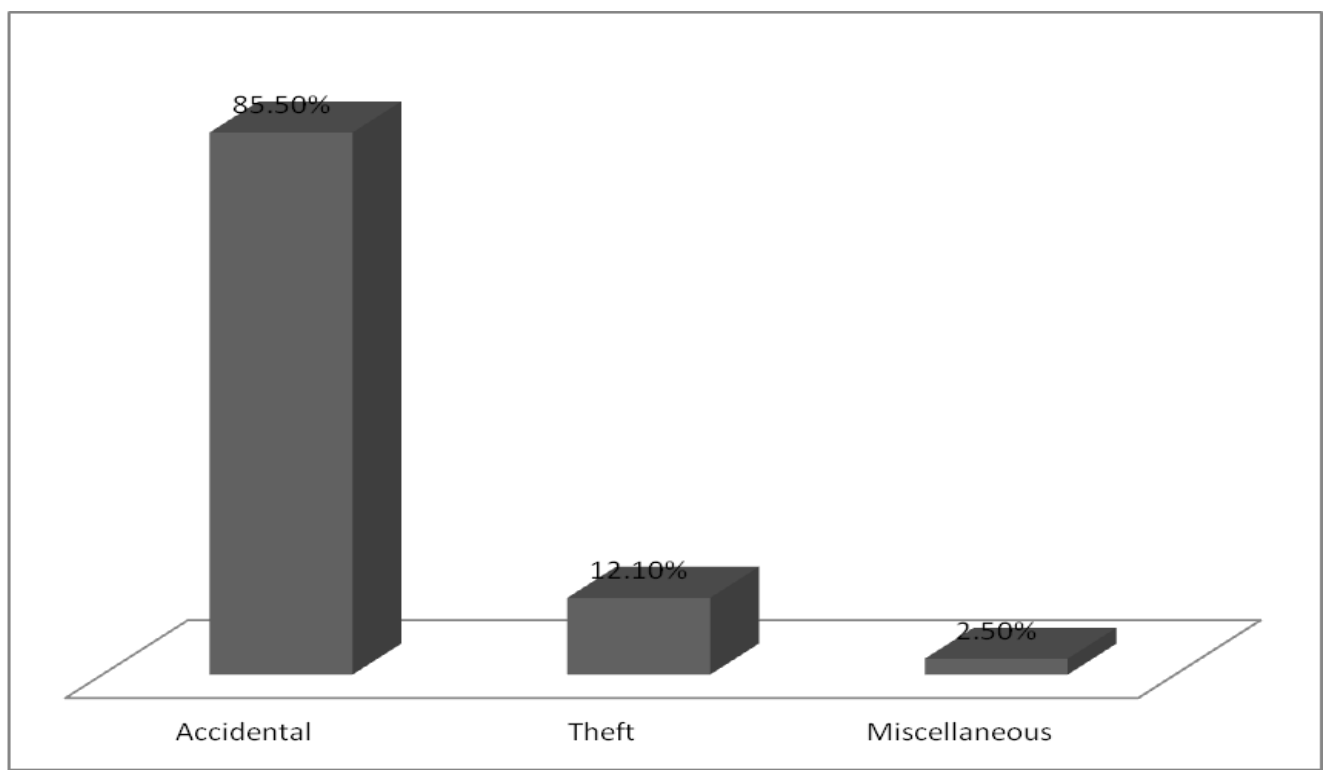

$N=27,230$

Figure 8 shows when the excuses are examined by commodity, again the overwhelming numbers are accidental. However, for jewellery and mobile phones theft, although small, accounts for a significantly larger number of excuses compared to the others, at around $10 \%$. Clearly this is yet another area which requires research against the insurers whole book of work.

Figure 8. Claimants' excuses by commodity

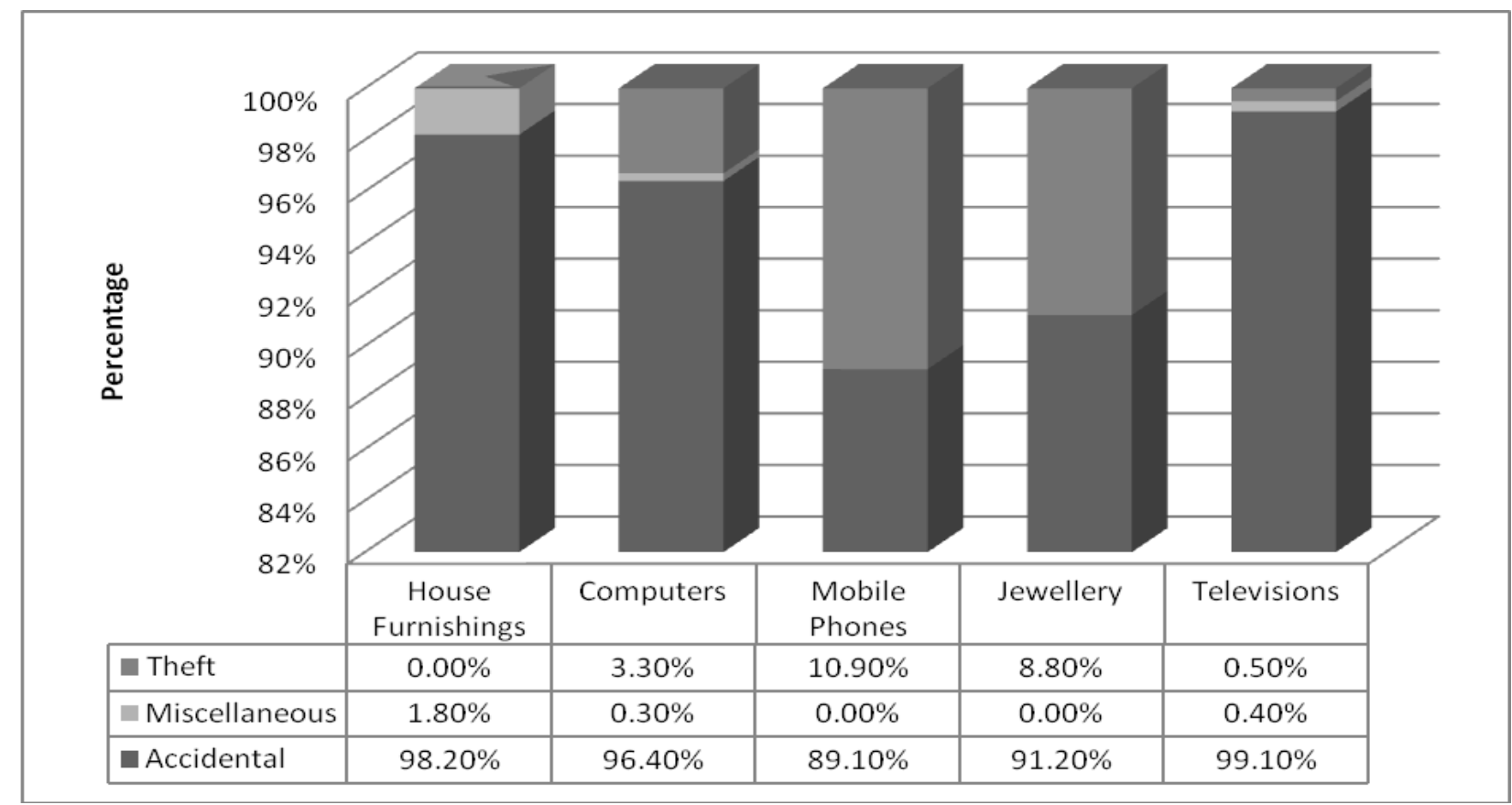


Figure 9. Dishonest claims by month

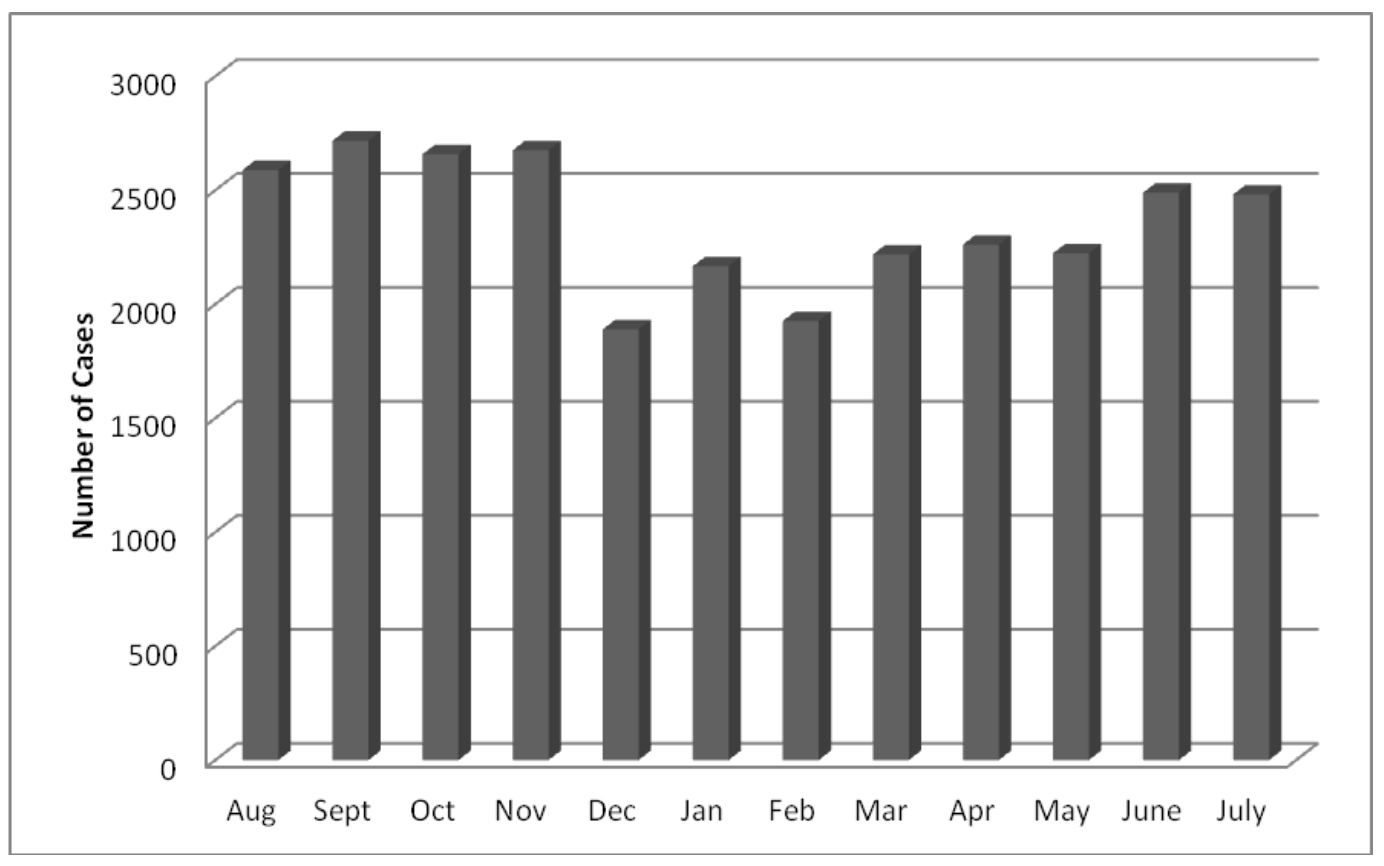

$\mathrm{N}=32,924$

\section{Time of claim}

The researchers were able to undertake analysis of when the claim was made. The data only distinguished by commodity item from June 2011 onwards. However, it was possible to assess all claims by the month they were submitted to see if there is a particular time of the year where people are more likely to submit a dishonest claim. We can see that the months from August to September see more claims forwarded to VFM than the rest of the year. Here we cannot discern an increase in claims either in the build-up to Christmas or in the run up to the summer holidays. See figure 9.

It was also possible to assess the smaller dataset related to specific types of commodities. This analysis is presented in figure 10. Here we find that for computers, mobile phones, jewellery and carpets the peak month is that of August. For televisions however, the busiest month for dishonest claims is October. We may assume that if fraudulent claims occur further to the claimants' everyday activities this may be the case for these commodities as well. It is well established that TV viewing figures are highest in winter and lowest in the summer. October may be the start of increased usage of the television when the evenings draw in and people spend more time inside. The peak in TV claims may coincide with the steepest seasonal increase in TV watching. This could also be related to the school holidays: parents who take time off work to look after the children may find themselves with more time to make a claim; a return from an expensive family holiday may also provide the motive for embellishing or fabricating a claim to settle the credit card bills. 
Figure 10. Dishonest claims by commodity by month

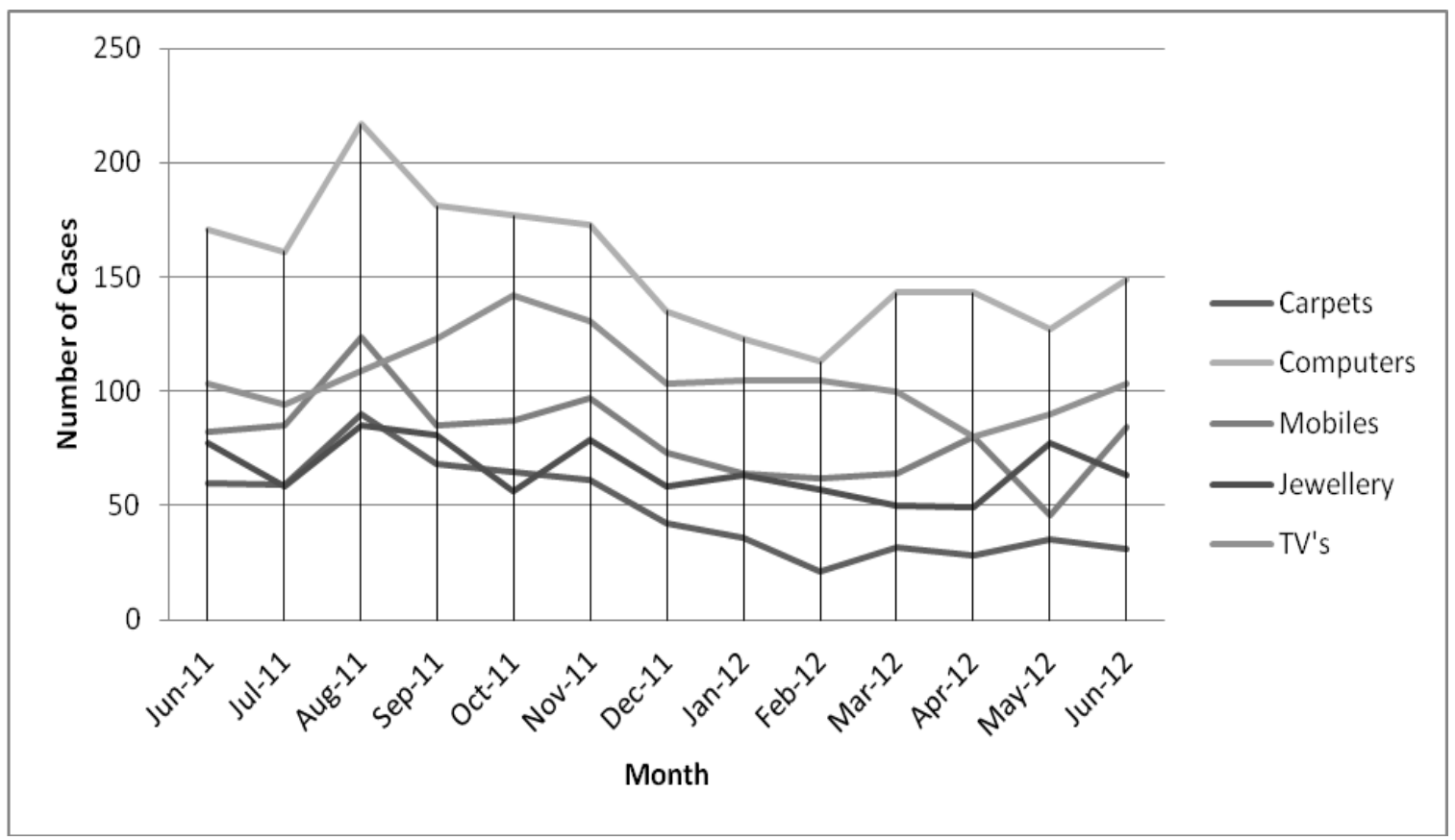

$\mathrm{N}=5,915$

\section{Conclusion}

Two main conclusions can be drawn from this analysis. The first is that dishonest household insurance claimants differ in their demographics from occupational fraudsters and they also present a very different picture from regular offenders, which tend to be in majority male and in their teens or early twenties (Newburn \& Stanko, 1994 p. 1). From that we may infer that household insurance fraud may come about through a different set of dynamics than regular crime and other types of fraud.

We suggest that 'Routine Activity Theory' emphasising the connection between crime and the everyday life and circumstances of offenders, is a useful lens through which these results can be examined. What is claimed by who and when is probably frequently connected to aspects of their everyday life. It is linked to the opportunity most householders have to exploit their contents insurance, motivated persons - on a significant scale - who believe it is acceptable to engage in insurance fraud or be ' a little dishonest' for a relatively small sum of money and a perception of an ineffective capable guardian ie the insurers.

Clearly there also needs to be more research on this subject. Further work on the geographical location and consumer classifications would provide useful information to add to the profile. Research based upon interviews with those who have submitted dishonest claims would also be useful to determine more conclusively the motivations and considerations of those who engage in such behaviour. 


\section{References:}

ACFE (2006) 2006 ACFE Report to the Nation on Occupational Fraud and Abuse. Austin: ACFE.

ACFE (2008) 2008 Report to the Nation on Occupational Fraud and Abuse. Austin: ACFE.

ACFE (2010) Report to the Nations on Occupational Fraud and Abuse. Austin: ACFE.

ACFE (2012). Report to the Nations on Fraud and Occupational Abuse. Austin: USA.

All In Employment By Status, Occupation \& Sex. (Apr - Jun 2012). Retrieved from Office for National Statistics website: http://www.ons.gov.uk/ons/publications/allreleases.html?definition=tcm\%3A7721588.Statisticsonsizeofthearmedforcesfromhttp://ww w.publications.parliament.uk/pa/cm201213/cmhansrd/cm121025/text/121025w0001.htm

Ariely, D. (2012) The (Honest) Truth About Dishonesty. London: Harper Collins

Association of British Insurers. (2003). What is Dishonest? Retrieved from http://www.abi.org.uk/Publications/24810.pdf

Association of British Insurers. (2012a). No Hiding Place: Insurance Fraud Exposed. London: Association of British Insurers.

Association of British Insurers. (2012b). UK Insurance Key Facts. London: Association of British Insurers.

Bussmann, K. D., \& Werle, M. M. (2006). Addressing Crime in Companies First Findings from a Global Survey of Economic Crime. British Journal of Criminology, 46, 11281144.

Canter, D. (1994). Criminal shadows< Inside the mind of the serial killer. London: Harper Collins.

Canter, D.V. and Heritage, R. (1990). A multivariate model of sexual offences behaviour: developments in 'offender profiling' I. Journal of Forensic Psychiatry, 1, 185-212.

Clarke, M. (1989). Insurance Fraud. British Journal of Criminology, 29, 1-20.

Clarke, M. (1990) The Control of Insurance Fraud A Comparative View. British Journal of Criminology, 30 1-23.

Cohen, L., E. and Felson, M. (1979) Social Change and Crime Rate Trends: A Routine Activities Approach. American Sociological Review, 44, pp 588-608. 
Davies, A. (1997). Specific Profile Analysis: a Data-based Approach to Offender Profiling. In J.L. Jackson, and D.A. Bekerian (eds.) (1997). Offender Profiling: Theory, Research and Practice. Chichester: Wiley.

Dodd, N., J. (1998) Insurance Claims Fraud: Applying Psychology to the Reduction of Insurance Claims Fraud. Insurance Trends, 18, pp 11-16.

Doig, A., Jones, B. and Wait, B. (1999) The Insurance Industry Response to Fraud. Security Journal, 12, pp 19-30.

Farrell, S , Yeo, N, \& Ladenburg, G. (2007). Blackstone's Guide to the Fraud Act 2006. Oxford: Oxford University Press.

Felson, M. (2002). Crime and Everyday Life: Insights and Implications for Society. Thousand Oaks, UK: Pine.

Felson, M. and Clarke, R., V., G. (1998) Opportunity Makes the Thief: Practical Theory for Crime Prevention. London: Home Office.

Gill, K., Woolley, A and Gill, M. (1994) Insurance Fraud: The Business as a Victim. In, Gill, M (ed) Crime at Work. Leicester: Perpetuity Press.

Jackson, J. and Bekerian, D. (1997) Offender profiling: Theory, research and practice. Chichester: Wiley.

Kapardis, A. \& Krambia-Kapardis, M (2004) Enhancing Fraud Prevention and Detection by Profiling Fraud Offenders. Journal of Criminal Behaviour and Mental Health, 14 (3), 189-201.

Karstedt, S., \& Farrall, S. (2006). The Moral Economy of Everyday Life. British Journal of Criminology, 46 (6): 10111036.

Koehnken, G., Milne, R., Memon, A., and Bull, R. (1999) The cognitive interview: A metaanalysis. Psychology, crime and law, 5, 3-17.

KPMG (2007) Profile of a Fraudster 2007 Survey. London: KPMG.

KPMG (2011). Who is the Typical Fraudster. London: KPMG.

Labour market data sourced from: Office for National Statistics (2012). Labour Market statistics, June 2012. Retrieved from http://www.ons.gov.uk/ons/dcp171778_265818.pdf

Levi, M. (2008) 'Organized Frauds and Organising Frauds: Unpacking the Research on Networks and Organisation', Criminology and Criminal Justice 8(4) :389-419. 
Litton, R., A. (2000) Criminological Research and the Insurance Industry. Security Journal, 13, pp 31-48.

Mazar, N., and Ariely, D. (2006). Dishonesty in Everyday Life and Its Policy Implications. Journal of Public Policy and Marketing, 25, 1-21.

McBride, N., J. and Bagsshaw, R. (2005). Tort Law. London: Longman. P435.

Memon, A., Vrij, A. and Bull, R. (2003) Psychology and law: Truthfulness, accuracy and credibility ( $2^{\text {nd }}$ edition). Chichester: Wiley.

Milne, R., and Bull, R. (1999). Investigative interviewing: Psychology and practice. Chichester: Wiley.

Morley, N. J., Ball, L. J. \& Ormerod, T.C. (2006). How the Detection of Insurance Fraud Succeeds and Fails. Psychology, Crime and Law, 12(2), 163-180.

National Fraud Authority (2012). Annual Fraud Indicator. London: NFA.

Newman, T., \& Stanko, E., A. (Eds.). (1994). Just Boys Doing Business? London: Routledge.

Palasinski, M. (2009) Testing Assumptions About Naivety in Insurance Fraud. Psychology, Crime and Law, 15, pp 547-553.

Smith, G., Button, M., Johnston, L. and Frimpong, F. (2010) Studying Fraud as White Collar Crime. Basingstoke: Palgrave.

Snook, B., Luther, K., Quinlan, H, and Milne, R. (2012) Let 'em Talk! A Field Study of Police Questioning Practices of Suspects and Accused Persons. Criminal justice and behavior, 39, 13281339.

Vrij, A. (2004) Why professionals fail to catch liars and how they can improve. Legal and criminological psychology, 9, 159-181.

Warfield, B. (2012) Million Dollar Employee Fraud in Australia. Australia: Warfield Associates

Wells, J., T. (1997). Occupational Fraud and Abuse. Dexter, Michigan: Obsidian.

Whiteley, P. (n.d.) Are Britons Getting More Dishonest? Retrieved 13 November 2012 from http://www.essex.ac.uk/government/research/are britons getting more dishonest.pdf 